\title{
Deep Brain Stimulation for Treatment-Refractory Mood and Obsessive-Compulsive Disorders
}

\author{
Alik S. Widge ${ }^{1,2,3} \cdot$ Darin D. Dougherty ${ }^{1}$
}

Published online: 29 August 2015

(C) Springer International Publishing AG 2015

\begin{abstract}
Deep brain stimulation (DBS) is an invasive therapy in which electrodes are surgically placed into the brain and deliver continuous electrical stimulation. It was originally developed for Parkinson's disease and other movement disorders. As evidence emerged that certain mental disorders involved abnormal function of specific brain nuclei, multiple investigators launched trials of DBS for mental disorders, particularly major depression (MDD) and obsessive-compulsive disorder (OCD). While open-label results were promising, recent large well-designed clinical trials in MDD have failed. We review the result of major DBS studies to date in psychiatry and what they have taught us about DBS' safety and efficacy. We further review a variety of animal and human neuroscience studies that have started to shed light on DBS' mechanisms of action at multiple brain targets. From these, we identify major trends that are likely to drive psychiatric DBS development in the coming decade, including "closed-loop" responsive stimulation, biomarker-based patient selection, and a better modeling of phenotypic heterogeneity within mental disorders. We conclude that on balance, DBS remains promising as a psychiatric treatment, but recent evidence highlights a clear need for further development and a better understanding of mechanisms.
\end{abstract}

This article is part of the Topical Collection on Mood and Anxiety Disorders

Alik S. Widge

awidge@partners.org

1 Department of Psychiatry, Massachusetts General Hospital and Harvard Medical School, Charlestown, MA, USA

2 Picower Institute for Learning \& Memory, Massachusetts Institute of Technology, Cambridge, MA, USA

3 Present address: 149 13th St., Room 2625, Charlestown, MA 02129, USA
Keywords Deep brain stimulation · Major depression · Obsessive-compulsive disorder $\cdot$ Neuromodulation

\section{Introduction}

Deep brain stimulation (DBS) is an invasive therapy in which implanted electrodes deliver high-frequency electrical stimulation to subcortical structures. While experiments in electrical brain stimulation have been ongoing almost since the discovery of electricity, the modern era of DBS is usually traced back to successful reports in the early 1990s for movement disorders [1]. Stereotactic lesions such as pallidotomy and thalamotomy were previously the state of the art in functional neurosurgery. As DBS began to replace those lesions, forward-thinking psychiatrists recognized that lesions of the dorsal anterior cingulate cortex and anterior limb of the internal capsule were known to be effective for treatment-resistant major depressive disorder (MDD) and obsessive-compulsive disorder (OCD) [2-6]; DBS was soon studied for these disorders as well. Early open-label results in both OCD and MDD were promising [7-9]. This spurred a round of pivotal controlled clinical trials, with great hope that DBS would unlock a new era of psychiatric cures.

With those blinded, sham-controlled trials now ending, the future seems less bright. One major controlled trial in MDD (St. Jude's BROADEN trial at the subgenual cingulate gyrus target) failed futility analyses while another (Medtronic's RECLAIM trial at the ventral internal capsule/ventral striatum target) demonstrated negative results $[10 \bullet \bullet$. The NIMHsponsored controlled trial for OCD closed in March 2015, and the first analyses may be available in late 2016. While it is now a standard of clinical care for Parkinson's disease, DBS in psychiatry remains mostly experimental. In this article, we will overview recent clinical trial results and early 
explorations of alternate anatomic targets. We will devote the majority of our discussion, however, to a discussion of what we can learn from these "failed" studies and how the field is moving forward. Our central thesis is that negative trial outcomes are not necessarily failures. Rather, they are an opportunity to begin understanding the mechanisms of DBS and its clinical effects. That understanding can inform the ongoing development of new brain stimulation technologies. By linking the two, we can begin to design therapies that truly engage the biological underpinnings of mental illness and perhaps finally realize DBS' clinical promise.

\section{State of the Clinical Art}

The majority of published studies cover two targets: the subgenual cingulate gyrus ( $\mathrm{sgCC}$ or $\mathrm{Cg} 25$ ) and the ventral internal capsule/ventral striatum (VC/VS), illustrated in Fig. 1. The latter was originally termed "anterior limb of internal capsule" (ALIC), but the name evolved as the target itself moved more posteriorly [7, 13, 14]. OCD was the first psychiatric disorder targeted with DBS, following the theory that DBS creates a "virtual lesion" of the stimulated tissue [7]. Initial positive results led to continued use and refinement of that target, and open-label results seemed promising. In a multicenter review of 26 cases, the mean improvement in Yale-Brown Obsessive-Compulsive Scale (YBOCS) score was $38 \%$, (from 34 to 21 ) with at least some clinical
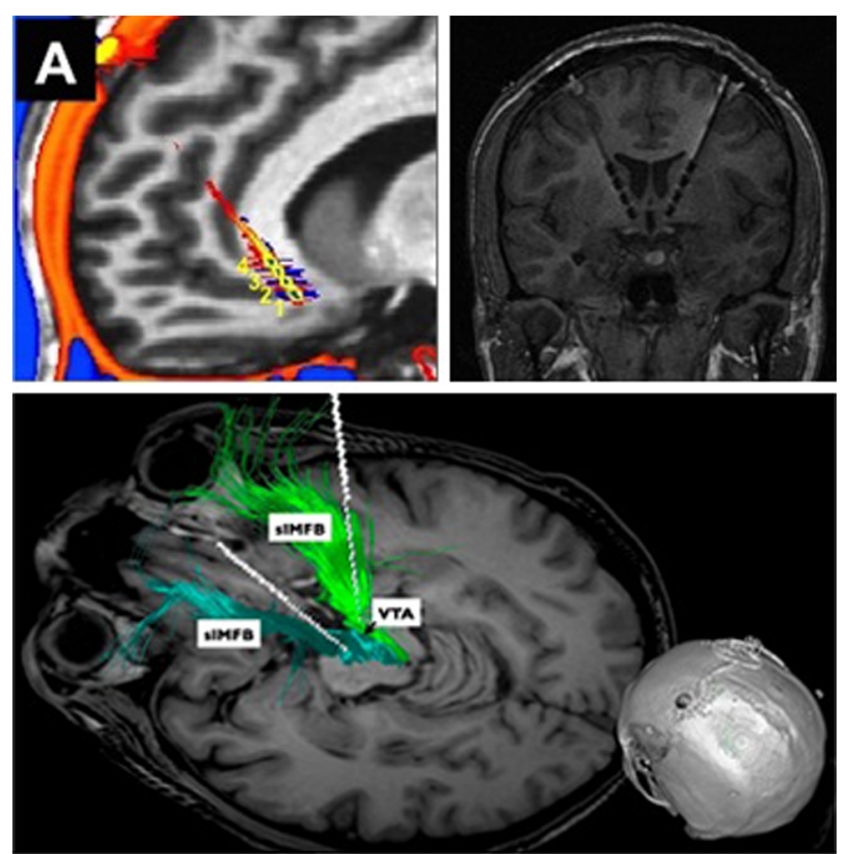

Fig. 1 Illustrations of DBS lead placement at three major targets. a Subgenual cingulate $(\mathrm{Cg} 25)$ for depression, from [11•]. b Ventral capsule/ventral striatum (VC/VS) for OCD and depression, from [9]. c Medial forebrain bundle (MFB) for depression, from [12•] response in $72 \%$ of patients [14]. Comorbid MDD also improved, with a mean drop of $43 \%$ in Montgomery-Asberg Depression Rating Scale (MADRS) and $50 \%$ of patients meeting criteria for depressive remission. That, in turn, led multiple groups to try DBS of VC/VS (and its close neighbor, the nucleus accumbens) for MDD. Open-label results were positive, with response and remission rates of 53 and $40 \%$, respectively $[9,15,16]$.

The Cg25 procedure had different origins, but a similar clinical path. Rather than being targeted based on historical lesion studies, $\mathrm{Cg} 25$ was repeatedly found to be hyperactive in neuroimaging of induced sad mood and in patients with severe MDD $[17,18]$. Again following the notion of DBS as a "virtual lesion", initial open-label results were promising, with a $43 \%$ remission rate at 6-year follow-up $[8,19]$. Importantly, $\mathrm{Cg} 25$ has never been studied for OCD, although there is evidence that surgical interventions for OCD modulate this target $[4,20]$. The results of these and closely related studies are summarized in Table 1.

Recently, those two streams have converged to apparent failure. The RECLAIM trial of VC/VS DBS for depression was stopped early after yielding negative results in an initial cohort of 30 patients with MDD [10••]. The BROADEN trial at $\mathrm{Cg} 25$ has not formally reported results, but the sponsor acknowledged an identical fate [26]. Poor results are not exclusive to mood and anxiety disorders; two recent early-stage trials of fornix and nucleus basalis DBS for Alzheimer's disease reported extremely modest cognitive outcomes [27, 28]. The only widely available psychiatric DBS procedure, particularly in the United States, is VC/VS DBS for OCD. This holds a Humanitarian Device Exemption from the US Food and Drug Administration (FDA), a class of approval granted when very few patients will ever be eligible for a therapy [29]. In theory, Humanitarian Device Exemption (HDE)-qualified treatments may never be required to complete a randomized controlled trial. In practice, investigators led by Butler Hospital/Brown University have attempted a multicenter controlled trial, which has just closed. ${ }^{1}$ This highlights an important point. Under the HDE, any surgeon may legally perform VC/VS DBS for OCD and receive financial reimbursement. In practice, it would be extremely inadvisable for anyone other than a well-trained and well-integrated team of psychiatrists and surgeons to attempt this procedure. The selection and management of these patients is exceptionally complex, they require specialized follow-up care, and psychiatric neurosurgery in general should only be performed after a thorough review of each case by a multidisciplinary committee [30].

Despite these apparent failures, DBS marches on. A medial forebrain bundle (MFB) target has shown positive openlabel results in MDD [12•,31] and is also shown in Fig. 1.

\footnotetext{
${ }^{1}$ Clinicaltrials.gov registry NCT00640133, accessed 1 June 2015.
} 
Table 1 Summary of completed and published studies in psychiatric DBS

\begin{tabular}{llllll}
\hline Target & Approval status (US) & Disorders & Open-label response rate & Largest study size & Key references \\
\hline VC/VS & HDE (OCD only) & MDD, OCD & $33-75 \%$ OCD, 26-53 \% MDD & 26 OCD, 30 MDD & {$[9,10 \bullet \cdot, 14,21]$} \\
Cg25 & Investigational & MDD & $29-92 \%$ & 21 & {$[19,22,23]$} \\
NAcc & Investigational & MDD, OCD & $37-56 \%$ OCD, 45 \% MDD & 16 OCD, 11 MDD & {$[16,24 \bullet, 25]$} \\
MFB & Investigational & MDD & $86 \%$ & 7 & {$[12 \bullet]$} \\
\hline
\end{tabular}

We have not included unpublished studies, e.g., the Cg25 BROADEN study or the recently completed VC/VS OCD trial

Cg25 Brodmann area 25 cingulate gyrus, $H D E$ Humanitarian Device Exemption, $M D D$ major depressive disorder, $M F B$ medial forebrain bundle, $N A c c$ nucleus accumbens, $O C D$ obsessive-compulsive disorder, $V C / V S$ ventral capsule/ventral striatum

The globus pallidus has been suggested for OCD, based on results in Tourette syndrome [32,33]. The amygdala is being used as a DBS target for post-traumatic stress disorder [34], and there have been small case series in autism [35], anorexia nervosa [36], and addiction [37]. The results above stand as a caution: it appears relatively easy to achieve openlabel improvement but quite difficult to move a DBS target through a well-designed randomized trial. We attribute those difficulties to a simple problem: we do not know what DBS actually does in any of these circuits. We thus do not know which patients are likely to respond, how to titrate stimulation parameters, or how to individualize the implant to a patient's anatomy. Until that is known, statistical noise will hamper DBS' development.

\section{Improving Clinical Targeting Through Neuro-Imaging}

While we work to define DBS' mechanisms of action, we can also refine our anatomic targeting. Psychiatric DBS is implanted at coordinates defined by the line connecting the anterior/posterior commissures, not by specific fibers. The anatomy of $\mathrm{Cg} 25$ and $\mathrm{VC} / \mathrm{VS}$ is heterogeneous among patients, and even experienced surgeons show variability in the ultimate electrode placement $[11 \bullet 38,39 \cdot \bullet]$. Simulations of the subthalamic nucleus (STN) suggest that even $1 \mathrm{~mm}$ of error can dramatically change what tissues are activated [40, 41]. The Mayberg group has recently identified a set of white matter tracts directly behind the $\mathrm{Cg} 25$ target that may drive improvement in MDD [11•]. Preliminary data suggest that similar rules may apply for VC/VS [42]. In the near future, we may be able to target DBS not to arbitrary coordinates but to defined white or gray matter structures that can be reliably localized for each patient. Other groups are developing "virtual patient simulation" tools to aid this [43, 44]. By simulating the tissue propagation of electrical and magnetic fields, it should become possible to place every DBS so to optimally capture the true functional target.

\section{Mechanisms: Clinical Correlates and Neural Biomarkers}

Anatomy is not the whole puzzle. The electrodes are usually near enough to the putative target to have some influence, but across studies, only about half of patients get better. Thus, the most pressing question is, "why does DBS work when it works?" With the growing number of clinical trial cases, investigators have begun to tackle that question through two avenues: understanding the clinical/behavioral correlates and searching for changes in brain activity.

\section{Clinical Correlates}

DBS takes weeks to months to produce improvement $[9,10 \bullet$, $14,21-23]$. This suggests that the mechanism is not a rapid recalibration of emotional circuits but may involve plasticity and learning. A favored theory is that DBS makes patients more able to benefit from other therapies, particularly cognitive-behavioral regimens. Evidence has now emerged to support that theory. Adding structured cognitivebehavioral therapy (CBT) for patients whose degree of response had plateaued from VC/VS DBS drove their YBOCS lower by a mean of 7.3 points [30॰]. This is impressive, given that all the patients (in accordance with DBS criteria) had tried CBT multiple times before without response. In patients receiving Cg25 DBS, one small ( $n=7)$ study found that electroencephalographic (EEG) markers of negative self-bias decreased with increasing exposure to DBS [45]. While this is not directly a psychotherapy study, negative self-talk is a core feature of MDD and is often targeted by CBT therapists.

Clinical correlates are not per se mechanisms but can point toward them. The suggestions of improved CBT response correlate with rat studies showing that VS DBS improves extinction learning in a conditioned fear protocol [46]. Extinction, which involves learning new safety memories, may be a correlate of human exposure/response-prevention (ERP) therapies [47, 48]. More recently, the same group has shown that VS DBS in rats increases brain-derived neurotrophic factor (BDNF) in multiple cortical regions [49] and seems to specifically modulate the orbitofrontal cortex (OFC) 
[50]. The former finding is intriguing given the apparent role of BDNF in MDD [51], while the latter points to the cortex that is frequently implicated in OCD $[52,53]$. This approach has limitations-VS DBS decreased fear responding in rats, but did not change fear-potentiated startle in humans [54]. Nevertheless, as we continue to identify subsets of patients and techniques to improve DBS' efficacy, this "reverse translation" strategy may be powerful.

There have also been attempts at forward translation, directly screening for DBS' behavioral effects in animal models. The strongest results have been found for the forced swim test, a putative model of learned helplessness in depression. Three groups have independently found that DBS given just before the test causes rats to struggle/swim for longer and spend less time immobile [55-57]. Interestingly, those results used very different targets, with one studying MFB [56] and the others finding effects for both the prefrontal cortex and nucleus accumbens (NAcc) [55, 57]. Neither study found effects on other model tests such as the elevated plus maze or sucrose preference (although see [58]). Further, the effect was not present in "healthy" animals; positive effects of DBS required the animals to already be in a "depressive" state, whether through genetic susceptibility [56] or chronic stress $[57,58]$. This work has difficulties, in particular the fact that the human DBS targets do not always have rodent correlates. MFB and NAcc have homologues, but rats have no internal capsule. They do have a Brodmann area 25 (the infralimbic cortex, or IL), but "Cg25" studies in rats often target DBS to the border of IL and its neighboring prelimbic cortex (PL) [55-58]. The fear-conditioning literature has shown these areas to have different and sometimes diametrically opposite behavioral effects [59-62]. Newer animal techniques such as optogenetics, which reliably offer greater circuit specificity, may improve our ability to tease out these circuits and their role in DBS [53, 63].

\section{Neural Biomarkers}

Clinically, DBS at every target seems to show dose-response correlation. "Dose" is difficult to quantify for a stimulus waveform with at least four degrees of freedom [64], but both response and side effects seem to correlate at least to current/ voltage amplitude [65]. In human and animal studies, DBS discontinuation causes a marked and often rapid "rebound" to a pathologic state $[22,25,66,67]$. It should therefore be possible to do "system identification"- to systematically vary DBS parameters, measure the brain's response, and through this identify the general mechanisms of DBS. Similar work with subthalamic nucleus (STN) DBS in Parkinson's patients has yielded valuable insights into impulsivity [68-70]. In OCD patients, switching VC/VS DBS on and off showed that DBS may decrease abnormally high functional connectivity (measured by resting-state fMRI) between cortex and striatum $[71 \bullet]$. This is concordant with a theory of OCD as hyperconnectivity in corticostriatal loops $[47,72,73]$ and with prior PET imaging that found DBS-induced metabolism increases in the OFC, putamen, and globus pallidus [20]. Magnetic resonance spectroscopy further linked VC/VS DBS to dopamine release in VS, although it did not in turn connect this to corticostriatal changes [74]. A recent acute discontinuation PET study at $\mathrm{Cg} 25$ was less revealing, finding changes in the dorsal cingulate, premotor cortex, and putamen, but not in $\mathrm{Cg} 25$ itself or its connected limbic structures [75]. However, in that study, the discontinuation caused little clinical effect, and thus, the intervention may itself have had insufficient "dose." The previously noted targeting results [11•] might also explain the lack of expected effect.

One under-explored domain in these studies is frequency, i.e., DBS' effect on the brain's endogenous oscillations. Those oscillations are believed to be a cross-species means for organizing circuits [76-78] and have been linked to a range of cognitive and emotional phenomena [79-83]. DBS is inherently an oscillatory intervention, which may serve to reset or modify endogenous rhythms [84-86]. Supporting that, one human study found a decrease in frontal low-frequency oscillations from VC/VS DBS [71••], while one rodent study found a decrease in fronto-hippocampal coherence from mixed IL/PL DBS [87]. A recent human study in Parkinson's disease found that DBS altered phase-amplitude coupling, a putative measure of neural ensemble coordination [88 ]. Linking psychiatric DBS to measures of cortical function that can resolve frequency-domain phenomena, e.g., EEG and magnetoencephalography, may both improve our understanding of DBS' mechanisms and shed further light on oscillations' role in cognition [89].

\section{Next Steps: Emerging Tools and Improving Techniques}

Although the clinical enthusiasm for DBS in mood and anxiety disorders has waned in the wake of two negative trials, researchers continue to advance both the basic neuroscience and clinical art. Those advances will be shaped by three trends in the coming decade: new physical techniques for stimulating below the cortex, new concepts of how to do psychiatric neuroscience, and the rise of responsive, "closedloop" DBS systems.

\section{New Stimulation Technologies}

Two trends are emerging: increased specificity and decreased invasiveness. To the first, DBS activates very heterogeneous populations. It captures both local cell bodies and passing axons, which in turn may conduct a signal throughout the 
brain. In many ways, this is similar to non-specific pharmacologic interventions. Given the emerging evidence that complex behaviors can be produced by modulating well-defined monosynaptic connections in animals [90-93], we might reasonably want DBS to target those same connections. Unfortunately, the animal results to date have involved permanent genetic modifications, a technique that is not immediately transferable to humans. Fortunately, there may be ways to achieve the same specificity with electrical stimulation. One rodent study recently showed that by combining electrical stimulation with a precise receptor blockade, optogeneticlike specificity may be achievable [94•]. There is also a long tradition of "coordinated" or "programmed" DBS, where complex pulse sequences are tailored to interference with known rhythms of a given nucleus. Simulation results suggest that these sequences can evoke plasticity and thus clinical effect from a subset of cells [84, 85]. Recently, a brief application of this "coordinated reset" paradigm in Parkinsonism produced motor improvements that lasted well past the end of stimulation, in contrast to the immediate wear-off of standard DBS [86]. Similar plasticity induction schemes could yield the specificity we seek in psychiatric circuits [63].

A major barrier to DBS' progress is the difficulty of enrolling patients in even early-phase studies, which in part relates to ethical concerns around psychiatric neurosurgery. A noninvasive or minimally invasive approach to brain stimulation would let us more rapidly "prototype" a variety of interventions. Transcranial magnetic stimulation (TMS) is far and away the most popular non-invasive stimulation modality in psychiatry. Unfortunately, it may be physically impossible to activate a deep structure with TMS without also activating overlying cortex [95, 96], although sequenced subthreshold stimulation has not been ruled out [97]. It may also be possible to reach deep targets by identifying patient-specific "cortical windows" that preferentially access them, but this still requires cortical activation [98]. One alternative would be to specifically alter the magnetic susceptibility of the target tissue, making it especially easy to activate with alternating magnetic fields. A recent study demonstrated this to be possible in mice using magnetic nanoparticles [99]. That effort again used genetic modifications, but the physical principles could be generalized to eliminate that barrier. It also requires injection of a small fluid volume into the brain, which might be accomplished with an endovascular approach. Finally, there has been a surge of interest in focused ultrasound (FUS). This was initially proposed as a lesion technology similar to stereotactic radiosurgery [100] or as a way to target chemotherapy to tumors [101]. More recently, it has been shown in animals and humans that low-intensity FUS can increase or decrease neural activity, in focused brain regions, without damaging the tissue [102-104]. If FUS transducers can be modified to reliably focus their energy in structures within the limbic circuit, this could become a non-invasive variant of DBS.

\section{Considering Overlap Across Disorders}

Above, we discussed studies that elucidate DBS' mechanisms by seeking patient characteristics or neural phenotypes that predict response. To date, that has been done within disorders, e.g., biomarkers of MDD response to Cg25 [89] or mechanisms of VC/VS DBS in OCD [71••]. These are powerful studies, but they discard a key fact: some DBS targets, especially VC/VS, have shown signal for both MDD and OCD $[9$, 14]. The same is true of lesion procedures such as anterior cingulotomy and anterior capsulotomy [5, 105, 106]. This invites a question: why should a single target be effective for two very different disorders? And why should we study those two disorders in isolation if they share a common pathway?

The answer, at least according to the National Institutes of Health (NIH), is that we should not. They have proposed realigning psychiatric neuroscience to "Research Domain Criteria" (RDoC), measurable behaviors that correspond more closely to psychological theory and animal neuroscience $[107$, 108]. Leaders from the research community have agreed, proposing that $\mathrm{RDoC}$ constructs could more tightly be linked to computational modeling that might aid treatment design [109]. For DBS, the implication is that we should target it not to diagnoses but to specific behaviors linked to the circuits and structures we are implanting. In that framework, Cg25 would become a "sad mood" DBS indication, while MFB would become "anhedonia" and VC/VS may improve "extinction learning."

The existence of useful transdiagnostic features is not mere speculation. A resting-state study of patients with generalized anxiety disorder (GAD) and/or MDD found that crossdiagnostic dimensions were necessary to fully explain the variation in an affective network covering cingulate, PFC, and striatum $[110 \bullet \cdot$. A cingulate-insula network shows morphometric changes across Axis I disorders [111•]. Closer to treatment, a single CBT protocol shows efficacy across mood and anxiety disorders as long as patients have evidence of emotional dysregulation [112]. We believe it should be possible to apply those insights to the design of the next round of DBS trials [113].

\section{Responsive, Closed-Loop Stimulation}

DBS is a static therapy. Patients' systems are programmed with fixed stimulation settings (sometimes with a chance to switch between two or three very similar "groups"), and those settings are then continuously applied for weeks at a time. Mental disorders, meanwhile, are not static. Obsessions, compulsions, panic, worry, hyper-arousal, and even mood symptoms can wax and wane dramatically on timescales of minutes to days. This creates a fundamental mismatch between the programmed therapy and the patient's immediate need. That by definition promotes both under-treatment and side effects; the mean "dose" necessary to control a patient's symptoms on 
average is guaranteed to be too much on some days and too little on others. As we expand the space of possible DBS indications, this becomes a greater problem. Consider anxiety and trauma-related disorders, where patients experience brief but intense flares of fear and distress. Assuming that a DBS target (e.g., amygdala) could be found to suppress that distress, a clinician in the present "open-loop" paradigm might set the DBS amplitude to ensure that the patient experienced symptoms less than once per week. During that week, the patient would spend most of his/her time receiving stimulation designed to suppress a flare that was not actually present. The result could easily be emotional "numbing", which is frequently unacceptable [114].

A better approach would be a system that tracks the current level of symptoms and titrates the degree of stimulation to match/suppress it. Such closed-loop systems are succeeding for neurologic disorders. They are marketed for epilepsy [115], and in laboratory models of Parkinson's have shown greater clinical efficiency than standard DBS [116]. Two things are still needed to bring these feedback-control systems into the world of psychiatric DBS: hardware platforms that can implement closed-loop strategies and a better understanding of brain signals that could provide the necessary feedback and symptom state detection.

The hardware platforms are rapidly emerging. A major DBS manufacturer has demonstrated a "sensing" system that can record from the human brain and provide those signals to clinicians [117] and has proven that it can be used for closedloop control in an epilepsy-like application $[118 \bullet, 119]$. On the animal side, several groups have demonstrated open hardware platforms that can readily be customized to enable closed-loop control of brain activity with commodity parts [120-122], and a system resembling those was successfully used for closedloop control of psychiatrically relevant brain areas in rodents [123•]. Biomarkers are the greater challenge. A closed-loop brain stimulation system operates by tracking an electrical signal in the brain and changing the stimulation parameters to drive the tracked signal to a desired range. There is no known brain signal that tightly tracks the symptoms of any mental disorder. Many have been proposed, but they generally are found in small, poorly powered studies and do not replicate well [124, 125]. Recently, our group has highlighted two ways past the biomarker barrier. First, there is a marker that is common to many disorders but often overlooked - a patient's own desire to be free of symptoms. Most mood and anxiety disorders are ego-dystonic. Patients recognize their symptoms as "not myself" and wish to be rid of them. We have proposed, and demonstrated in an animal model, that it is possible to control a psychiatric brain stimulator by reading out the user's intention - an explicit mental command to the stimulator [114, 123•]. This model, which owes much to the development of "neural prosthetics" for motor paralysis, may be a useful tool for improving patients' self-regulation ability across diagnoses. That leads into the second way forward-moving past diagnoses. We discussed above the possibility that a transdiagnostic paradigm could help better target DBS. It may also help identify biomarkers. Electrical brain activity presumably reflects circuit function. By identifying circuits that are impaired across disorders, we may find the electrical features we need $[108,124]$. Our group is now 1 year into a 5year program to test that theory. ${ }^{2} \mathrm{We}$ have defined initial metrics for the transdiagnostic states [126-128] and designed novel devices that can use them to drive treatment $[129,130]$.

\section{Conclusions}

DBS for mood and obsessive-compulsive disorders has recently faced challenges, but we see reasons for optimism. The continued proliferation of targets and potential indications shows that the research community's enthusiasm and commitment have not diminished. The failure of trials based on simplistic targeting justifies a more rational, neuroscience-driven approach to DBS' development. Key to that will be studies where we ensure that every patient contributes something to our understanding of the underlying biology. That may include "serial $n$ of 1 " or other adaptive designs and will likely involve the use of devices that can record and report on the brain during therapy. Through that, the next decade should yield a much better knowledge of DBS' mechanisms of action, which should in turn translate to greater clinical efficacy. Just as importantly, it may allow us to define non-DBS approaches to modulating the same structures. That will expand the availability of novel neurotherapeutics to far more patients. There is a bright future ahead for specific and focal brain-based treatments in psychiatry, and with continued refinement, DBS will be a valuable part of that arsenal.

Acknowledgments DDD has received research support from and served on advisory panels for Medtronic and Cyberonics. Both authors are named inventors on patent applications related to transdiagnostic targeting of brain stimulation interventions and methods for closed-loop deep brain stimulation. Both authors gratefully acknowledge the support of the DARPA SUBNETS program, cooperative agreement W911NF-142-0045. ASW is also supported by the Picower Family Foundation.

\section{Compliance with Ethics Guidelines}

Conflict of Interest Darin Dougherty received a federal research grant from DARPA, a device donation from Medtronic, funding from the NIH, payment from Cyberonics for presentations related to vagus nerve stimulation, and payment from Medtronic for training physicians in the use of DBS for OCD. Alik Widge received a federal research grant from DARPA, an individual fellowship from Picower Family Foundation, and funding from the $\mathrm{NIH}$, and Widge has patents applied related to novel deep brain stimulation treatments.

\footnotetext{
${ }^{2} \mathrm{http} / / /$ transformdbs.partners.org
} 
Human and Animal Rights and Informed Consent This article does not contain any studies with human or animal subjects performed by the author.

\section{References}

Papers of particular interest, published recently, have been highlighted as:

- Of importance

•. Of major importance

1. Benabid AL, Pollak P, Hoffmann D, Gervason C, Hommel M, Perret JE, et al. Long-term suppression of tremor by chronic stimulation of the ventral intermediate thalamic nucleus. Lancet. 1991;337:403-6. doi:10.1016/0140-6736(91)91175-T.

2. Bingley T, Leksell L, Meyerson B, Rylander G. Long-term results of stereotactic capsulotomy in chronic obsessive compulsive neurosis. Neurosurgery. Treat. Psychiatry Pain Epilepsy, University Park Press; 1977, p. 287-9.

3. Ballantine Jr HT, Bouckoms AJ, Thomas EK, Giriunas IE. Treatment of psychiatric illness by stereotactic cingulotomy. Biol Psychiatry. 1987;22:807-19.

4. Rauch SL, Dougherty DD, Cosgrove GR, Cassem EH, Alpert $\mathrm{NM}$, Price $\mathrm{BH}$, et al. Cerebral metabolic correlates as potential predictors of response to anterior cingulotomy for obsessive compulsive disorder. Biol Psychiatry. 2001;50:659-67.

5. Dougherty DD, Baer L, Cosgrove GR, Cassem EH, Price BH, Nierenberg AA, et al. Prospective long-term follow-up of 44 patients who received cingulotomy for treatment-refractory obsessive-compulsive disorder. Am J Psychiatry. 2002;159:269-75. doi:10.1176/appi.ajp.159.2.269.

6. Montoya A, Weiss AP, Price BH, Cassem EH, Dougherty DD, Nierenberg AA, et al. Magnetic resonance imaging-guided stereotactic limbic leukotomy for treatment of intractable psychiatric disease. Neurosurgery. 2002;50:1043-52.

7. Nuttin B, Cosyns P, Demeulemeester H, Gybels J, Meyerson B. Electrical stimulation in anterior limbs of internal capsules in patients with obsessive-compulsive disorder. Lancet. 1999;354: 1526. doi:10.1016/S0140-6736(99)02376-4.

8. Mayberg HS, Lozano AM, Voon V, McNeely HE, Seminowicz D, Hamani C, et al. Deep brain stimulation for treatment-resistant depression. Neuron. 2005;45:651-60. doi:10.1016/j.neuron. 2005.02.014

9. Malone DA, Dougherty DD, Rezai AR, Carpenter LL, Friehs GM, Eskandar EN, et al. Deep brain stimulation of the ventral capsule/ ventral striatum for treatment-resistant depression. Biol Psychiatry. 2009;65:267-75. doi:10.1016/j.biopsych.2008.08.029.

10.• Dougherty DD, Rezai AR, Carpenter LL, Howland RH, Bhati MT, O'Reardon JP, et al. A randomized sham-controlled trial of deep brain stimulation of the ventral capsule/ventral striatum for chronic treatment-resistant depression. Biol Psychiatry. 2015;78: $240-8$. This is the most recent study of DBS for major depression and the largest published randomized trial of psychiatric DBS.

11. Holtzheimer PE, Kelley ME, Gross RE, Filkowski MM, Garlow SJ, Barrocas A, et al. Subcallosal cingulate deep brain stimulation for treatment-resistant unipolar and bipolar depression. Arch Gen Psychiatry. 2012;69:150-8. doi:10.1001/archgenpsychiatry.2011. 1456. This is the largest study published at the Cg25 target and showed very strong open-label response in unipolar and bipolar depression.
12. Schlaepfer TE, Bewernick BH, Kayser S, Mädler B, Coenen VA. Rapid effects of deep brain stimulation for treatment-resistant major depression. Biol Psychiatry. 2013;73:1204-12. doi:10.1016/j. biopsych.2013.01.034. This is the first published series at the MFB target and showed unusually fast changes in depression symptoms.

13. Okun MS, Mann G, Foote KD, Shapira NA, Bowers D, Springer $\mathrm{U}$, et al. Deep brain stimulation in the internal capsule and nucleus accumbens region: responses observed during active and sham programming. J Neurol Neurosurg Psychiatry. 2007;78:310-4. doi:10.1136/jnnp.2006.095315.

14. Greenberg B, Gabriels L, Malone D, Rezai A, Friehs G, Okun M, et al. Deep brain stimulation of the ventral internal capsule/ventral striatum for obsessive-compulsive disorder: worldwide experience. Mol Psychiatry. 2010;15:64-79. doi:10.1038/mp.2008.55.

15. Bewernick BH, Hurlemann R, Matusch A, Kayser S, Grubert C, Hadrysiewicz B, et al. Nucleus accumbens deep brain stimulation decreases ratings of depression and anxiety in treatment-resistant depression. Biol Psychiatry. 2010;67:110-6. doi:10.1016/j. biopsych.2009.09.013.

16. Bewernick BH, Kayser S, Sturm V, Schlaepfer TE. Long-term effects of nucleus accumbens deep brain stimulation in treatment-resistant depression: evidence for sustained efficacy. Neuropsychopharmacology. 2012;37:1975-85. doi:10.1038/npp. 2012.44.

17. Mayberg HS, Liotti M, Brannan SK, McGinnis S, Mahurin RK, Jerabek PA, et al. Reciprocal limbic-cortical function and negative mood: converging pet findings in depression and normal sadness. Am J Psychiatry. 1999;156:675-89.

18. Mayberg HS. Targeted electrode-based modulation of neural circuits for depression. J Clin Invest. 2009;119:717-25. doi:10.1172/ JCI38454.

19. Kennedy SH, Giacobbe P, Rizvi SJ, Placenza FM, Nishikawa Y, Mayberg HS, et al. Deep brain stimulation for treatment-resistant depression: follow-up after 3 to 6 years. Am J Psychiatry. 2011;168:502-10.

20. Rauch SL, Dougherty DD, Malone DA, Rezai A, Friehs G, Fischman AJ, et al. A functional neuroimaging investigation of deep brain stimulation in patients with obsessive-compulsive disorder. J Neurosurg. 2006;104:558-65.

21. Goodman WK, Foote KD, Greenberg BD, Ricciuti N, Bauer R, Ward H, et al. Deep brain stimulation for intractable obsessive compulsive disorder: pilot study using a blinded, staggered-onset design. Biol Psychiatry. 2010;67:535-42.

22. Lozano AM, Giacobbe P, Hamani C, Rizvi SJ, Kennedy SH, Kolivakis TT, et al. A multicenter pilot study of subcallosal cingulate area deep brain stimulation for treatment-resistant depression. J Neurosurg 2011:1-8. doi: 10.3171/2011.10.JNS102122.

23. Denys D, Mantione M, Figee M, van den Munckhof P, Koerselman F, Westenberg H, et al. Deep brain stimulation of the nucleus accumbens for treatment-refractory obsessive-compulsive disorder. Arch Gen Psychiatry. 2010;67:1061-8. doi:10. 1001/archgenpsychiatry.2010.122.

24. Mantione M, Nieman DH, Figee M, Denys D. Cognitive-behavioural therapy augments the effects of deep brain stimulation in obsessive-compulsive disorder. Psychol Med. 2014;44:3515-22. doi:10.1017/S0033291714000956. This was the first evidence confirming the generally held hypothesis that DBS at VC/VS works by improving the patient's benefit from cognitive therapy.

25. Gálvez JF, Keser Z, Mwangi B, Ghouse AA, Fenoy AJ, Schulz $\mathrm{PE}$, et al. The medial forebrain bundle as a deep brain stimulation target for treatment resistant depression: a review of published data. Prog Neuropsychopharmacol Biol Psychiatry. 2015;58:5970. doi:10.1016/j.pnpbp.2014.12.003. 
26. Morishita T, Fayad SM, Higuchi M, Nestor KA, Foote KD. Deep brain stimulation for treatment-resistant depression: systematic review of clinical outcomes. Neurotherapeutics. 2014;11:475-84. doi:10.1007/s13311-014-0282-1.

27. Sankar T, Chakravarty MM, Bescos A, Lara M, Obuchi T, Laxton AW, et al. Deep brain stimulation influences brain structure in Alzheimer's disease. Brain Stimulat n.d. doi:10.1016/j.brs.2014. 11.020 .

28. Kuhn J, Hardenacke K, Lenartz D, Gruendler T, Ullsperger M, Bartsch C, et al. Deep brain stimulation of the nucleus basalis of Meynert in Alzheimer's dementia. Mol Psychiatry. 2015;20:35360. doi:10.1038/mp.2014.32.

29. Garnaat SL, Greenberg BD, Sibrava NJ, Goodman WK, Mancebo MC, Eisen JL, et al. Who qualifies for deep brain stimulation for OCD? Data from a naturalistic clinical sample. J Neuropsychiatry Clin Neurosci. 2014;26:81-6. doi:10.1176/appi.neuropsych. 12090226.

30. Widge AS, Dougherty DD. Managing patients with psychiatric disorders with deep brain stimulation. In: Marks Jr WJ, editor. Deep brain stimul. Manag. 2nd ed. Cambridge: Cambridge University Press; 2015.

31. Silburn P. Deep brain stimulation of anteromedial globus pallidus interna for severe Tourette's syndrome. Am J Psychiatry. 2012;169:860. doi:10.1176/appi.ajp.2012.11101583.

32. Nair G, Evans A, Bear RE, Velakoulis D, Bittar RG. The anteromedial GPi as a new target for deep brain stimulation in obsessive compulsive disorder. J Clin Neurosci. 2014;21:81521. doi:10.1016/j.jocn.2013.10.003.

33. Koek RJ, Langevin J-P, Krahl SE, Kosoyan HJ, Schwartz HN, Chen JW, et al. Deep brain stimulation of the basolateral amygdala for treatment-refractory combat post-traumatic stress disorder (PTSD): study protocol for a pilot randomized controlled trial with blinded, staggered onset of stimulation. Trials. 2014;15:356. doi: 10.1186/1745-6215-15-356.

34. Sturm V, Fricke O, Bührle CP, Lenartz D, Maarouf M, Treuer H, et al. DBS in the basolateral amygdala improves symptoms of autism and related self-injurious behavior: a case report and hypothesis on the pathogenesis of the disorder. Front Hum Neurosci 2013;6. doi:10.3389/fnhum.2012.00341.

35. Lipsman N, Woodside DB, Giacobbe P, Hamani C, Carter JC, Norwood SJ, et al. Subcallosal cingulate deep brain stimulation for treatment-refractory anorexia nervosa: a phase 1 pilot trial. Lancet. 2013. doi:10.1016/S0140-6736(12)62188-6.

36. Kuhn J, Möller M, Treppmann JF, Bartsch C, Lenartz D, Gruendler TOJ, et al. Deep brain stimulation of the nucleus accumbens and its usefulness in severe opioid addiction. Mol Psychiatry. 2014;19:145-6. doi:10.1038/mp.2012.196.

37. Hamani C, Mayberg H, Stone S, Laxton A, Haber S, Lozano AM. The subcallosal cingulate gyrus in the context of major depression. Biol Psychiatry. 2011;69:301-8. doi:10.1016/j.biopsych.2010.09. 034.

38. Haber SN, Heilbronner SR. Translational research in OCD: circuitry and mechanisms. Neuropsychopharmacology. 2013;38: 252-3. doi:10.1038/npp.2012.182.

39.• Riva-Posse P, Choi KS, Holtzheimer PE, McIntyre CC, Gross RE, Chaturvedi A, et al. Defining critical white matter pathways mediating successful subcallosal cingulate deep brain stimulation for treatment-resistant depression. Biol Psychiatry. 2014;76:963-9. doi:10.1016/j.biopsych.2014.03.029. This very elegant paper identifies a possible mechanism for response vs. nonresponse in Cg25 DBS for depression.

40. McIntyre CC, Mori S, Sherman DL, Thakor NV, Vitek JL. Electric field and stimulating influence generated by deep brain stimulation of the subthalamic nucleus. Clin Neurophysiol. 2004;115: 589-95. doi:10.1016/j.clinph.2003.10.033.
41. Butson CR, Cooper SE, Henderson JM, McIntyre CC. Patientspecific analysis of the volume of tissue activated during deep brain stimulation. NeuroImage. 2007;34:661-70. doi:10.1016/j. neuroimage.2006.09.034.

42. Hartmann C, Lujan J, Chaturvedi A, Goodman W, Okun M, McIntyre C, et al. Tractography activation patterns in dorsolateral prefrontal cortex suggest better clinical responses in deep brain stimulation (DBS) of the anterior limb of the internal capsule and nucleus accumbens (ALIC-NA) for obsessive-compulsive disorder (OCD). Neurology. 2015;84:P6.191.

43. Bonmassar G, Angelone LM, Makris N. A virtual patient simulator based on human connectome and 7 T MRI for deep brain stimulation. Int J Adv Life Sci. 2014;6:364-72.

44. Horn A, Kühn AA. Lead-DBS: a toolbox for deep brain stimulation electrode localizations and visualizations. NeuroImage. 2015;107:127-35. doi:10.1016/j.neuroimage.2014.12.002.

45. Hilimire MR, Mayberg HS, Holtzheimer PE, Broadway JM, Parks NA, DeVylder JE, et al. Effects of subcallosal cingulate deep brain stimulation on negative self-bias in patients with treatmentresistant depression. Brain Stimul. 2015;8:185-91. doi:10.1016/ j.brs.2014.11.010.

46. Rodriguez-Romaguera J, Do Monte FH, Quirk GJ. Deep brain stimulation of the ventral striatum enhances extinction of conditioned fear. Proc Natl Acad Sci. 2012;109:8764-9.

47. Milad MR, Rauch SL. Obsessive-compulsive disorder: beyond segregated cortico-striatal pathways. Trends Cogn Sci. 2012;16: 43-51. doi:10.1016/j.tics.2011.11.003.

48. Milad MR, Furtak SC, Greenberg JL, Keshaviah A, Im JJ, Falkenstein MJ, et al. Deficits in conditioned fear extinction in obsessive-compulsive disorder and neurobiological changes in the fear circuit. JAMA Psychiatry. 2013;70:608. doi:10.1001/ jamapsychiatry.2013.914.

49. Do-Monte FH, Rodriguez-Romaguera J, Rosas-Vidal LE, Quirk GJ. Deep brain stimulation of the ventral striatum increases BDNF in the fear extinction circuit. Front Behav Neurosci 2013;7. doi:10. 3389/fnbeh.2013.00102.

50. Rodriguez-Romaguera J, Do-Monte FH, Tanimura Y, Quirk GJ, Haber SN. Enhancement of fear extinction with deep brain stimulation: evidence for medial orbitofrontal involvement. Neuropsychopharmacology. 2015;40:1726-33. doi:10.1038/npp. 2015.20.

51. Molendijk ML, Spinhoven P, Polak M, Bus BA, Penninx BWJH, Elzinga BM. Serum BDNF concentrations as peripheral manifestations of depression: evidence from a systematic review and meta-analyses on 179 associations $(\mathrm{N}=9484)$. Mol Psychiatry. 2014;19:791-800. doi:10.1038/mp.2013.105.

52. Dougherty DD, Rauch SL, Greenberg BD. Pathophysiology of obsessive compulsive disorders. In: Stein DJ, Hollander E, editors. Textb. Anxiety disord. Washington, DC: American Psychiatric Publishing; 2010. p. 287-310.

53. Ahmari SE, Dougherty DD. Dissecting OCD circuits: from animal models to targeted treatments. Depress Anxiety. 2015. doi:10. 1002/da.22367.

54. Baas JMP, Klumpers F, Mantione MH, Figee M, Vulink NC, Schuurman PR, et al. No impact of deep brain stimulation on fear-potentiated startle in obsessive-compulsive disorder. Front Behav Neurosci 2014;8. doi:10.3389/fnbeh.2014.00305.

55. Hamani C, Amorim BO, Wheeler AL, Diwan M, Driesslein K, Covolan L, et al. Deep brain stimulation in rats: different targets induce similar antidepressant-like effects but influence different circuits. Neurobiol Dis. 2014;71:205-14. doi:10.1016/j.nbd. 2014.08.007.

56. Edemann-Callesen H, Voget M, Empl L, Vogel M, Wieske F, Rummel J, et al. Medial forebrain bundle deep brain stimulation has symptom-specific anti-depressant effects in rats and as opposed to ventromedial prefrontal cortex stimulation interacts with 
the reward system. Brain Stimul. 2015. doi:10.1016/j.brs.2015.02. 009 .

57. Lim LW, Prickaerts J, Huguet G, Kadar E, Hartung H, Sharp T, et al. Electrical stimulation alleviates depressive-like behaviors of rats: investigation of brain targets and potential mechanisms. Transl Psychiatry. 2015;5, e535. doi:10.1038/tp.2015.24.

58. Hamani C, Machado DC, Hipólide DC, Dubiela FP, Suchecki D, Macedo CE, et al. Deep brain stimulation reverses anhedonic-like behavior in a chronic model of depression: role of serotonin and brain derived neurotrophic factor. Biol Psychiatry. 2012;71:30-5. doi:10.1016/j.biopsych.2011.08.025.

59. Herry C, Ferraguti F, Singewald N, Letzkus JJ, Ehrlich I, Lüthi A. Neuronal circuits of fear extinction. Eur J Neurosci. 2010;31:599 612. doi:10.1111/j.1460-9568.2010.07101.x.

60. Milad MR, Quirk GJ. Fear extinction as a model for translational neuroscience: ten years of progress. Annu Rev Psychol. 2012;63: 129-51. doi:10.1146/annurev.psych.121208.131631.

61. Bravo-Rivera C, Roman-Ortiz C, Brignoni-Perez E, Sotres-Bayon F, Quirk GJ. Neural structures mediating expression and extinction of platform-mediated avoidance. J Neurosci. 2014;34:9736-42. doi:10.1523/JNEUROSCI.0191-14.2014.

62. Likhtik E, Paz R. Amygdala-prefrontal interactions in (mal)adaptive learning. Trends Neurosci. 2015;38:158-66. doi: 10.1016/j.tins.2014.12.007.

63. Tye KM. Neural circuit reprogramming: a new paradigm for treating neuropsychiatric disease? Neuron. 2014;83:1259-61. doi:10.1016/j.neuron.2014.08.022.

64. Peterchev AV, Wagner TA, Miranda PC, Nitsche MA, Paulus W, Lisanby SH, et al. Fundamentals of transcranial electric and magnetic stimulation dose: definition, selection, and reporting practices. Brain Stimul. 2012;5:435-53. doi:10.1016/j.brs.2011.10.001.

65. Luigjes J, Mantione M, van den Brink W, Schuurman PR, van den Munckhof P, Denys D. Deep brain stimulation increases impulsivity in two patients with obsessive-compulsive disorder: Int Clin Psychopharmacol 2011:1. doi:10.1097/YIC.0b013e32834af505.

66. Ewing SG, Grace AA. Long-term high frequency deep brain stimulation of the nucleus accumbens drives time-dependent changes in functional connectivity in the rodent limbic system. Brain Stimul. 2013;6:274-85. doi:10.1016/j.brs.2012.07.007.

67. Ooms P, Blankers M, Figee M, Mantione M, van den Munckhof P, Schuurman PR, et al. Rebound of affective symptoms following acute cessation of deep brain stimulation in obsessive-compulsive disorder. Brain Stimul. 2014;7:727-31. doi:10.1016/j.brs.2014. 06.009 .

68. Ballanger B, van Eimeren T, Moro E, Lozano AM, Hamani C, Boulinguez $\mathrm{P}$, et al. Stimulation of the subthalamic nucleus and impulsivity: release your horses. Ann Neurol. 2009;66:817-24. doi:10.1002/ana.21795.

69. Cavanagh JF, Wiecki TV, Cohen MX, Figueroa CM, Samanta J, Sherman SJ, et al. Subthalamic nucleus stimulation reverses mediofrontal influence over decision threshold. Nat Neurosci. 2011;14:1462-7. doi:10.1038/nn.2925.

70. Boller JK, Barbe MT, Pauls KAM, Reck C, Brand M, Maier F, et al. Decision-making under risk is improved by both dopaminergic medication and subthalamic stimulation in Parkinson's disease. Exp Neurol n.d. doi:10.1016/j.expneurol.2014.01.005.

71.• Figee M, Luigjes J, Smolders R, Valencia-Alfonso C-E, van Wingen G, de Kwaasteniet B, et al. Deep brain stimulation restores frontostriatal network activity in obsessive-compulsive disorder. Nat Neurosci. 2013;16:386-7. doi:10.1038/nn.3344. This was one of the first human mechanistic studies of DBS in OCD, identifying a frontal and striatal network that changes in response to DBS.

72. Graybiel AM, Rauch SL. Toward a neurobiology of obsessivecompulsive disorder. Neuron. 2000;28:343-7. doi:10.1016/ S0896-6273(00)00113-6.
73. Anticevic A, Hu S, Zhang S, Savic A, Billingslea E, Wasylink S, et al. Global resting-state functional magnetic resonance imaging analysis identifies frontal cortex, striatal, and cerebellar dysconnectivity in obsessive-compulsive disorder. Biol Psychiatry. 2014;75:595-605. doi:10.1016/j.biopsych.2013.10.021.

74. Figee M, de Koning P, Klaassen S, Vulink N, Mantione M, van den Munckhof P, et al. Deep brain stimulation induces striatal dopamine release in obsessive-compulsive disorder. Biol Psychiatry. 2014;75:647-52. doi:10.1016/j.biopsych.2013.06.021.

75. Martín-Blanco A, Serra-Blasco M, Pérez-Egea R, de DiegoAdeliño J, Carceller-Sindreu M, Puigdemont D, et al. Immediate cerebral metabolic changes induced by discontinuation of deep brain stimulation of subcallosal cingulate gyrus in treatmentresistant depression. J Affect Disord. 2015;173:159-62. doi:10. 1016/j.jad.2014.10.035.

76. Buzsáki G, Watson BO. Brain rhythms and neural syntax: implications for efficient coding of cognitive content and neuropsychiatric disease. Dialogues Clin Neurosci. 2012;14:345.

77. Buzsáki G, Logothetis N, Singer W. Scaling brain size, keeping timing: evolutionary preservation of brain rhythms. Neuron. 2013;80:751-64. doi:10.1016/j.neuron.2013.10.002.

78. Anastassiou CA, Koch C. Ephaptic coupling to endogenous electric field activity: why bother? Curr Opin Neurobiol. 2015;31:95103. doi:10.1016/j.conb.2014.09.002.

79. Buschman TJ, Denovellis EL, Diogo C, Bullock D, Miller EK. Synchronous oscillatory neural ensembles for rules in the prefrontal cortex. Neuron. 2012;76:838-46. doi:10.1016/j.neuron.2012. 09.029 .

80. Hasselmo ME, Stern CE. Theta rhythm and the encoding and retrieval of space and time. NeuroImage. 2014;85(Part 2):65666. doi:10.1016/j.neuroimage.2013.06.022.

81. Likhtik E, Gordon JA. Circuits in sync: decoding theta communication in fear and safety. Neuropsychopharmacology. 2014;39: 235-6. doi:10.1038/npp.2013.228.

82. Stujenske JM, Likhtik E, Topiwala MA, Gordon JA. Fear and safety engage competing patterns of theta-gamma coupling in the basolateral amygdala. Neuron. 2014;83:919-33. doi:10. 1016/j.neuron.2014.07.026.

83. Brincat SL, Miller EK. Frequency-specific hippocampal-prefrontal interactions during associative learning. Nat Neurosci. 2015;18:576-81. doi:10.1038/nn.3954.

84. Tass PA. A model of desynchronizing deep brain stimulation with a demand-controlled coordinated reset of neural subpopulations. Biol Cybern. 2003;89:81-8. doi:10.1007/s00422-003-0425-7.

85. Tass PA, Hauptmann C. Therapeutic modulation of synaptic connectivity with desynchronizing brain stimulation. Int J Psychophysiol. 2007;64:53-61. doi:10.1016/j.ijpsycho.2006.07.013.

86. Adamchic I, Hauptmann C, Barnikol UB, Pawelczyk N, Popovych O, Barnikol TT, et al. Coordinated reset neuromodulation for Parkinson's disease: proof-of-concept study. Mov Disord. 2014;29:1679-84. doi:10.1002/mds.25923.

87. Insel N, Pilkiw M, Nobrega JN, Hutchison WD, TakeharaNishiuchi K, Hamani C. Chronic deep brain stimulation of the rat ventral medial prefrontal cortex disrupts hippocampal-prefrontal coherence. Exp Neurol. 2015;269:1-7. doi:10.1016/j. expneurol.2015.03.023.

88. De Hemptinne C, Swann NC, Ostrem JL, Ryapolova-Webb ES, San Luciano M, Galifianakis NB, et al. Therapeutic deep brain stimulation reduces cortical phase-amplitude coupling in Parkinson's disease. Nat Neurosci. 2015;18:779-86. doi:10. $1038 /$ nn.3997. This is a complement to the Figee et al. study that identifies network oscillatory signatures of successful DBS in Parkinsons disease.

89. Smart OL, Tiruvadi VR, Mayberg HS. Multimodal approaches to define network oscillations in depression. Biol Psychiatry n.d. doi: 10.1016/j.biopsych.2015.01.002. 
90. Gerits A, Farivar R, Rosen BR, Wald LL, Boyden ES, Vanduffel W. Optogenetically induced behavioral and functional network changes in primates. Curr Biol. 2012;22:1722-6. doi:10.1016/j. cub.2012.07.023.

91. Aston-Jones G, Deisseroth K. Recent advances in optogenetics and pharmacogenetics. Brain Res. 2013;1511:1-5. doi:10.1016/j. brainres.2013.01.026.

92. Ahmari SE, Spellman T, Douglass NL, Kheirbek MA, Simpson $\mathrm{HB}$, Deisseroth K, et al. Repeated cortico-striatal stimulation generates persistent OCD-like behavior. Science. 2013;340:1234-9. doi:10.1126/science. 1234733 .

93. Steinberg EE, Christoffel DJ, Deisseroth K, Malenka RC. Illuminating circuitry relevant to psychiatric disorders with optogenetics. Curr Opin Neurobiol. 2015;30:9-16. doi:10.1016/ j.conb.2014.08.004.

94. Creed M, Pascoli VJ, Lüscher C. Refining deep brain stimulation to emulate optogenetic treatment of synaptic pathology. Science. 2015;347:659-64. doi:10.1126/science.1260776. The first known demonstration of optogenetic-like specificity using only electrical stimulation and pharmacology. This illustrates how optogenetics could inform DBS development.

95. Deng Z-D, Lisanby SH, Peterchev AV. Electric field depthfocality tradeoff in transcranial magnetic stimulation: simulation comparison of 50 coil designs. Brain Stimul. 2013;6:1-13. doi:10. 1016/j.brs.2012.02.005.

96. Deng Z-D, Lisanby SH, Peterchev AV. Coil design considerations for deep transcranial magnetic stimulation. Clin Neurophysiol. 2014;125:1202-12. doi:10.1016/j.clinph.2013.11.038.

97. Roth Y, Padberg F, Zangen A. Transcranial magnetic stimulation of deep brain regions: principles and methods. Adv Biol Psychiatr. 2007;23:204-25.

98. Wang JX, Rogers LM, Gross EZ, Ryals AJ, Dokucu ME, Brandstatt KL, et al. Targeted enhancement of corticalhippocampal brain networks and associative memory. Science. 2014;345:1054-7. doi:10.1126/science. 1252900.

99. Chen R, Romero G, Christiansen MG, Mohr A, Anikeeva P. Wireless magnetothermal deep brain stimulation. Science. 2015;347:1477-80. doi:10.1126/science.1261821.

100. Elias WJ, Huss D, Voss T, Loomba J, Khaled M, Zadicario E, et al. A pilot study of focused ultrasound thalamotomy for essential tremor. N Eng1 J Med. 2013;369:640-8. doi:10.1056/ NEJMoa1300962.

101. Liu H-L, Yang H-W, Hua M-Y, Wei K-C. Enhanced therapeutic agent delivery through magnetic resonance imaging-monitored focused ultrasound blood-brain barrier disruption for brain tumor treatment: an overview of the current preclinical status. Neurosurg Focus. 2012;32:E4

102. Tufail Y, Yoshihiro A, Pati S, Li MM, Tyler WJ. Ultrasonic neuromodulation by brain stimulation with transcranial ultrasound. Nat Protoc. 2011;6:1453-70. doi:10.1038/nprot.2011.371.

103. Yoo S-S, Bystritsky A, Lee J-H, Zhang Y, Fischer K, Min B-K, et al. Focused ultrasound modulates region-specific brain activity. NeuroImage. 2011;56:1267-75. doi:10.1016/j.neuroimage.2011. 02.058 .

104. Legon W, Sato TF, Opitz A, Mueller J, Barbour A, Williams A, et al. Transcranial focused ultrasound modulates the activity of primary somatosensory cortex in humans. Nat Neurosci. 2014;17:322-9. doi:10.1038/nn.3620.

105. Lopes A, Greenberg B, Canteras M, Batistuzzo M, Hoexter M, Gentil A, et al. Gamma ventral capsulotomy for obsessivecompulsive disorder: a randomized clinical trial. JAMA Psychiatry. 2014;71:1066-76. doi:10.1001/jamapsychiatry.2014.1193.

106. Yang JC, Ginat DT, Dougherty DD, Makris N, Eskandar EN. Lesion analysis for cingulotomy and limbic leucotomy: comparison and correlation with clinical outcomes. J Neurosurg. 2013. doi:10.3171/2013.9.JNS13839.
107. Insel TR, Wang PS. Rethinking mental illness. J Am Med Assoc. 2010;303:1970-1. doi:10.1001/jama.2010.555.

108. Cuthbert BN, Insel TR. Toward the future of psychiatric diagnosis: the seven pillars of RDoC. BMC Med. 2013;11:126. doi:10.1186/ 1741-7015-11-126.

109. Wang X-J, Krystal JH. Computational psychiatry. Neuron. 2014;84:638-54. doi:10.1016/j.neuron.2014.10.018.

110.• Oathes DJ, Patenaude B, Schatzberg AF, Etkin A. Neurobiological signatures of anxiety and depression in resting-state functional magnetic resonance imaging. Biol Psychiatry. 2015;77:385-93. doi:10.1016/j.biopsych.2014.08.006. This was one of the first studies to show that neither a categorical diagnostic scheme nor a dimension-based classification can fully explain mental symptoms, and that both frameworks are needed in concert.

111. Goodkind M, Eickhoff SB, Oathes DJ, Jiang Y, Chang A, JonesHagata LB, et al. Identification of a common neurobiological substrate for mental illness. JAMA Psychiatry. 2015;72:305. doi:10. 1001/jamapsychiatry.2014.2206. Initial morphometric evidence that cross-diagnostic neuroscience and treatment is both feasible and reasonable.

112. Ellard KK, Fairholme CP, Boisseau CL, Farchione TJ, Barlow $\mathrm{DH}$. Unified protocol for the transdiagnostic treatment of emotional disorders: protocol development and initial outcome data. Cogn Behav Pract. 2010;17:88-101. doi:10.1016/j.cbpra.2009.06.002.

113. Widge AS, Deckersbach T, Eskandar EN, Dougherty DD. Deep brain stimulation for treatment-resistant psychiatric illnesses: what has gone wrong and what should we do next? Biol Psychiatry. 2015. doi:10.1016/j.biopsych.2015.06.005.

114. Widge AS, Dougherty DD, Moritz CT. Affective brain-computer interfaces as enabling technology for responsive psychiatric stimulation. Brain-Comput Interfaces. 2014;1:126-36. doi:10.1080/ 2326263X.2014.912885.

115. Morrell MJ. Responsive cortical stimulation for the treatment of medically intractable partial epilepsy. Neurology. 2011;77:1295304. doi:10.1212/WNL.0b013e3182302056.

116. Rosin B, Slovik M, Mitelman R, Rivlin-Etzion M, Haber SN, Israel $\mathrm{Z}$, et al. Closed-loop deep brain stimulation is superior in ameliorating Parkinsonism. Neuron. 2011;72:370-84. doi:10. 1016/j.neuron.2011.08.023.

117. Rouse AG, Stanslaski SR, Cong P, Jensen RM, Afshar P, Ullestad $\mathrm{D}$, et al. A chronic generalized bi-directional brain-machine interface. J Neural Eng. 2011;8:036018. doi:10.1088/1741-2560/8/3/ 036018.

118. Afshar P, Khambhati A, Carlson D, Dani S, Lazarewicz M, Cong $\mathrm{P}$, et al. A translational platform for prototyping closed-loop neuromodulation systems. Front Neural Circuits. 2013;6:117. doi:10.3389/fncir.2012.00117. Describes a novel hardware platform specifically designed for responsive, symptomlocked DBS.

119. Stypulkowski PH, Stanslaski SR, Jensen RM, Denison TJ, Giftakis JE. Brain stimulation for epilepsy - local and remote modulation of network excitability. Brain Stimul. 2014;7:350-8. doi:10.1016/j.brs.2014.02.002.

120. Rolston JD, Gross RE, Potter SM. Closed-loop, open-source electrophysiology. Front Neurosci 2010;4. doi:10.3389/fnins.2010. 00031.

121. Siegle JH, Hale GJ, Newman JP, Voigts J. Neural ensemble communities: open-source approaches to hardware for large-scale electrophysiology. Curr Opin Neurobiol. 2015;32:53-9. doi:10.1016/ j.conb.2014.11.004.

122. Wu H, Ghekiere H, Beeckmans D, Tambuyzer T, van Kuyck K, Aerts J-M, et al. Conceptualization and validation of an opensource closed-loop deep brain stimulation system in rat. Sci Rep. 2015;4:9921. doi:10.1038/srep09921.

123. Widge AS, Moritz CT. Pre-frontal control of closed-loop limbic neurostimulation by rodents using a brain-computer interface. J 
Neural Eng. 2014;11:024001. doi:10.1088/1741-2560/11/2/ 024001. A first preliminary demonstration that closed-loop control of psychiatric circuits and symptoms is possible, using a rodent model.

124. Kapur S, Phillips AG, Insel TR. Why has it taken so long for biological psychiatry to develop clinical tests and what to do about it? Mol Psychiatry. 2012;17:1174-9. doi:10.1038/mp.2012.105.

125. Widge AS, Avery DH, Zarkowski P. Baseline and treatmentemergent EEG biomarkers of antidepressant medication response do not predict response to repetitive transcranial magnetic stimulation. Brain Stimul. 2013;6:929-31. doi:10.1016/j.brs.2013.05.001.

126. Faghih RT, Stokes PA, Marin M-F, Zsido RG, Zorowitz S, Rosenbaum BL, et al. Characterization of fear conditioning and fear extinction by analysis of electrodermal activity. Proc 37th Annu Int Conf IEEE Eng Med Biol Soc EMBC 2015 n.d.:to appear.
127. Yousefi A, Paulk AC, Deckersbach T, Dougherty DD, Eskandar EN, Widge AS, et al. Cognitive state prediction using an EM algorithm applied to gamma distributed data. Proc 37th Annu Int Conf IEEE Eng Med Biol Soc EMBC 2015 n.d.:to appear.

128. Deng X, Faghih RT, Barbieri R, Paulk AC, Asaad WF, Brown EN, et al. Estimating a dynamic state to relate neural spiking activity to behavioral signals during cognitive tasks. Proc 37th Annu Int Conf IEEE Eng Med Biol Soc EMBC 2015 n.d.:to appear.

129. Bjune CK, Marinis TF, Brady JM, Moran J, Wheeler JJ, Sriram TS, et al. Package architecture and component design for an implanted neural stimulator with closed loop control. Proc 37th Annu Int Conf IEEE Eng Med Biol Soc EMBC 2015 n.d.:to appear.

130. Wheeler JJ, Baldwin K, Kindle A, Guyon D, Nugent B, Segura C, et al. An implantable 64-channel neural interface with reconfigurable recording and stimulation. Proc 37th Annu Int Conf IEEE Eng Med Biol Soc EMBC 2015 n.d.:to appear. 